\title{
Trends in Family-Centered Care in Neonatal Intensive Care
}

\author{
Maree, Carin PhD; Downes, Fiona MS (MCur-Neonatal Nursing) \\ Department of Nursing Science, University of Pretoria, Pretoria, South Africa (Dr Maree and Ms Downes); and \\ Nursetech, Midrand, South Africa (Ms Downes). \\ Corresponding Author: Carin Maree, PhD, Department of Nursing Science, University of Pretoria 0028, South \\ Africa (carin.maree@up.ac.za or maree.carin@gmail.com).
}

The article is based on concepts from a study done for partial completion of a master's degree in neonatal nursing by means of course work at the Department of Nursing Science, University of Pretoria. A special word of appreciation for Dr Shahirose Premji for her guidance and support to finalize the article.

Disclosure: The authors have disclosed that they have no significant relationships with, or financial interest in, any commercial companies pertaining to this article.

\begin{abstract}
Family-centered care in neonatal intensive care changed over the last decades. Initially, parents and infants were separated and parents were even being blamed for causing infections in their infants. The importance, though, of the parents being the constant in the infant's life emerged and with that the importance of early bonding and attachment for the parents to take on their role and responsibilities as primary caregivers. Facilitation of family-centered care includes involving the parents in daily care activities, kangaroo care, developmental care, interaction and communication with the infant, as well as involving grandparents and siblings. Implementation of family-centered care requires appropriate policies, facilities and resources, education of all involved, and a positive attitude.
\end{abstract}

Key Words: family-centered care, historical trends, neonatal intensive care

The 1960s were a significant milestone in the field of neonatology with the introduction of neonatal intensive care units (NICUs) to provide specialized healthcare for immediate survival and physical care of sick and prematurely born infants. ${ }^{1}$ Paradoxically, the resulting separation of newborns and parent(s) during a crucial period of bonding and attachment was found to have adverse consequences for both. ${ }^{2}$ The birth of a premature or sick newborn can have devastating effects on parents, including fear and stress, helplessness, ${ }^{3}$ and posttraumatic stress disorder. ${ }^{4}$ The NICU environment can negatively influence neurobehavioral outcomes of infants. ${ }^{5}$

To counter the negative impact of the NICU, family-centered care (FCC) emerged as a comprehensive and holistic approach, placing each infant's needs within the family structure or family and community context while addressing medical needs. ${ }^{2}$ Johnson et al ${ }^{6}$ described FCC as a philosophy of care where the family's role is recognized and respected as being essential. Stress and negative outcomes are reduced through parent/family involvement in care activities, communication and education, ${ }^{7,8}$ group and individual therapy and support systems, ${ }^{9}$ and consideration of age-specific needs (eg, needs of a teenage mother). ${ }^{3}$ In the NICU context, family often refers to the neonate, the mother, and the father, but it can include grandparents, extended family members, significant other(s) identified by the 
mother/father, and the sibling(s). This article provides an overview of FCC in the NICU and reports on FCC trends reflected in the literature from 1960 to 2015. This review can assist nurses to consider changes in their own practice to promote FCC and anticipate future directions in practice and policy changes.

\section{HISTORICAL OVERVIEW OF FCC IN THE NICU}

In Victorian times, mothers were considered the best nurses and separation of mother and child was discouraged. ${ }^{10}$ Family-centered care was a natural extension from birth. Infants were born at home, and elder women would help the new mother in the postpartum period. ${ }^{2}$ Prematurely born or sick infants commonly died at home. ${ }^{11,12}$ Special care of premature infants was initiated in the late 1800s by Tarnier (obstetrician and the grandfather of perinatology) and Budin (pediatrician), which decreased mortality. ${ }^{11,13}$ Couney, a mentee of Budin, then initiated exhibitions in Europe and America of premature infants in kinderbrutanstalt (child hatchery). ${ }^{11,13}$ Mademoiselle Louise Recht was the first neonatal nurse to lead the nursing staff in caring for these infants by giving them gavage and nasal feedings of breast milk obtained from wet nurses. ${ }^{11,13}$ The infants were separated from their mothers, but mothers could attend the exhibitions at no cost, which they did infrequently. If the infants survived and they were no longer suitable for exhibition, they were returned to their mothers, but Couney had difficulty persuading parents to assume their parental responsibilities. ${ }^{11}$ Care of the premature infants was considered to be of good quality and many more survived, but there was not a trace of FCC. Idiopathic failure to thrive was common among the infants in the months after discharge, and they were often returned to the hospital battered. ${ }^{14}$

Hess opened the first premature nursery in Chicago in 1914, based on the principles of Cooney.11,13 Infants were cared for by nurses who were trained by Recht and Lundeen, a mentee of Recht. Parents were not present or involved. ${ }^{11,13}$ Many similar nurseries were established. Jackson introduced rooming-in for the first time in a premature nursery at Yale in 1944 , and in 1949, she used skin-to-skin contact for 1 to $1 \frac{1 / 2}{2}$ hours after birth. ${ }^{12}$ These practices were perhaps the first traces of FCC. The 1950s saw various attempts at saving premature babies in special nurseries. ${ }^{15}$ However, many of these babies died only a day or two after birth, which was attributed to "germs" from the parents. Parents were subsequently banned from having contact with their newborns. ${ }^{13,15}$ Jackson allowed parents into the premature nursery to see and handle their babies, although this was against the law at the time. ${ }^{8}$

The first true NICU was established in 1960 in Yale-New Haven Hospital. ${ }^{12}$ Articles published in the 1960s and 1970s reported mainly on small, premature babies who perished after a few days. Parents were not considered as important in the infants' care in the NICU and the main focus remained on the medical care of illness, with few exceptions. ${ }^{16,17}$ Auerbach ${ }^{16}$ highlighted the importance of involvement by means of breast-feeding, and Dunn and White ${ }^{17}$ focused on interaction after birth. Parents were still commonly excluded from the NICU, with limited visiting time and no involvement in care activities. The 1980s marked the introduction of studies relating to mother-infant bonding that later informed FCC in neonatal practice. ${ }^{18}$ From then on, there was a gradual movement away from a pure medical approach to NICU FCC.

\section{TRENDS RELATED TO FCC}

A review of the literature shows that FCC has progressed in NICU care. A number of themes were identified from 1960 to 2015 that exemplify the varied ways in which FCC came to 
prominence.

\section{Interaction, communication, and visitation}

Studies in the 1980s reported on bonding and interaction between parents and their infants, with positive influences on the newborn. ${ }^{17}$ The scope broadened in the 1990s from bonding to parental visitation, communication, and implementation of FCC, but emphasized the limited uptake of knowledge, with FCC not always being practiced. ${ }^{19}$ Family-centered care practice includes open visitation for parents to be present, and nurses facilitating interaction and communication between infants and their parents at birth or as soon as possible after. ${ }^{7,8}$

\section{Parental involvement in care activities}

Various degrees of parental involvement in care activities were reported through the decades related to kangaroo care, breast-feeding, developmental care, and decision making.

\section{Kangaroo care}

Jackson introduced aspects of kangaroo care in 1944, although the terms "kangaroo care" and "skin-to-skin contact" were not yet used. ${ }^{12}$ The concept of kangaroo care and the importance of skin-to-skin contact between the parent and the infant have received more attention in the literature since 2000. Hunt ${ }^{20}$ emphasized the importance of kangaroo care in which the parents could have physical contact with the infant sooner after birth and for longer periods. Identified constraints for kangaroo care include time, space, and lack of protocols ${ }^{20}$ or the staff not seeing the importance of the practice for preterm infants. ${ }^{21}$ Nurses are the link between the mother and her premature infant and therefore need good understanding and knowledge of kangaroo care, with the responsibility to implement it whenever possible. ${ }^{21}$

\section{Breast-feeding}

The importance of human milk and breast-feeding grew since the 1980s, with research and practice emphasized the challenges experienced by mothers to breast-feed their preterm infants, their needs for assistance to breast-feed, and how to support them and their partners. ${ }^{3,12,22-24}$ Auerbach ${ }^{16}$ discussed how the mother can feel valued by expressing breast milk for her infant. Although nurses promote human milk feedings for the purpose of nutrition, breast-feeding itself remains a priority in the NICU for its contribution to motherinfant bonding. Breast-feeding should be introduced within 2 hours after birth. Breast-feeding contributes to bon-ding, as it enhances interaction and communication between the mother and her baby, skin to skin contact, and the mother's experience of being the primary caregiver of her baby. ${ }^{25}$

\section{Developmental care}

The concept of developmental care with FCC as a core principle emerged during the 2000s to bridge the practice gap of FCC implementation and appreciate the family's central role in promoting infant development. ${ }^{26}$ Sizun and Westrup ${ }^{27}$ defined developmental care as the use of a range of medical and nursing interventions to decrease the stress of preterm neonates in NICUs, including the engaging parents in the daily care program. The developmental care approach shifts the focus of care away from the advanced technology in the NICU to the human element as a crucial component of care to reduce infant stress levels. ${ }^{28}$ Infants are seen as human beings in their own right, with nurses having a primary role in ensuring care is 
directed by the infants (ie, based on response to cues) and their families to reduce stress resulting from the NICU environment ${ }^{26}$ Moreover, nurses should recognize parents and their significant supports as a constant factor in the infant's life. ${ }^{5,27}$

\section{Decision making}

Parents' involvement in decision making regarding their infants' care in the NICU shifted from complete exclusion ${ }^{13}$ to being part of the multidisciplinary care team ${ }^{.25-29}$ Inclusion of parents as partners in decision making is faced with several challenges such as the parents' understanding of consequences of their decisions, their experience of decision making as a burden, and their relationship with the NICU staff. The staff are responsible for forming a partnership with the parents, keeping them informed, and negotiating for decisions in the infant's best interest. Involving parents in decision making assists them in assuming their role as primary caretakers. ${ }^{26,29}$

\section{Family support systems, grandparents, and siblings}

The relevance of family support systems in the delivery of FCC emerged in the 1990s. ${ }^{30}$ Parents' need for support became an important consideration, with special attention on including fathers and approaches for supporting them ${ }^{.7,18,31-33}$ The parents' social system, which might include grandparents, other family members, or significant others, became an important area of consideration to reduce stress and assist parents in coping with the hospitalization of their newborn infant. ${ }^{34}$ Siblings have often been excluded from the NICU, but they should be involved, as they form part of the constant in the infant's life after discharge. Their involvement should include an introduction to their new brother/sister, be age-appropriate, prepare them for what to expect, and create a sense of being part of the family process. ${ }^{35}$

\section{Implementation of family-centered care}

Family-centered care contributes to family engagement, decision making, and infant care, ${ }^{19,36}$ and implementation requires a suitable physical layout, resources, policies, and a positive attitude. These issues have become dominant in the discourse on FCC and the following are some best practices in relation to each.

\section{Physical layout and resources}

Adequate space and privacy are considerations. ${ }^{37}$ Resources should make provision for the parents' physical needs, such as food and rest. ${ }^{36,38}$ Involvement of grandparents and siblings should be kept in mind during the planning and allocation of resources ${ }^{.38}$ These factors are important in administering FCC, but not all must be in place to implement FCC.

\section{Policies}

Institutional management should endorse policies ${ }^{36}$ for successful and sustainable implementation of safe, evidence-based FCC in the NICU to optimize care for a very vulnerable population. ${ }^{5,36,38}$ Policies should be informed by parents', siblings', and other support persons' needs through active involvement ${ }^{38}$ and should include issues related to neonatal nurses' training and practice in the delivery of FCC. ${ }^{7}$ Family should be foundational to policy implementation. 


\section{Neonatal staff's attitude}

Family-centered care is complex, requiring a mind shift from task-focused, routine care to individualized, infant/family-focused care. It should be based on reciprocal partnership between families and healthcare workers, ${ }^{39}$ with 2-way communication and nurses being in relationship with families. ${ }^{7}$ Neonatal nurses must recognize the impact their interactions and relationships have on families ${ }^{33}$ and "be present" when interacting with parents and their social networks.

\section{RECOMMENDATIONS FOR FCC}

The following recommendations can be made for practice and policies:

* Parents should be placed centrally in the care of their newborn infant in the NICU, and siblings should be introduced to the infant as soon as it is practically possible.

* Evidence-based policies for NICUs need to be written, with parents and family members as an integral part of the process.

* The principles and application of FCC should be included in all formal curricula for healthcare workers who are working in NICUs.

* Continuing education should be provided to the NICU staff to ensure that the concept of FCC forms the core of nursing practice.

Research should continue on FCC in the NICU, especially to examine the impact of FCC on long-term outcomes of infants and their families.

Best practice guidelines for person-centered care and FCC are available from the Registered Nurses' Association of Ontario (RNAO) ${ }^{40}$ that can be applied in NICU. Griffin and Celenza ${ }^{41}$ offer a comprehensive guide for FCC for healthy, ill, or preterm newborns, and the Institute for Patient- and Family-Centered Care ${ }^{42}$ (www.ipfcc.org) provides resources and information for implementation. The preferred future is to advance family-integrated care as described by O'Brien et al, ${ }^{29}$ where parents are empowered through a structured process to participate in their infant's care as members of the multidisciplinary team and not standing on the sideline. This approach might lead both to stronger bonding, attachment, and taking responsibility for the long-term care of the infant and to improved outcomes for infants and their families.

\section{CONCLUSION}

Hospitalization of infants began in the 1900s, but mothers were only allowed to see their infants to breast-feed when hospitalized. Separation of children and mothers during hospitalization continued under the belief that parents were responsible for infant morbidity and mortality. In the 1970s, parents were allowed to see their infant in the ward just a few days before discharge. During the 1960s to the 1980s, FCC slowly emerged and became more prominent from the 1990s. It became a central part of neonatal intensive care from 2010 onward, but with challenges and variations in implementation of strategies such as interaction, communication, and visitation; parental involvement in care activities (kangaroo care, breast-feeding, developmental care, and decision making); family support systems, grandparents and siblings; and full implementation of FCC (physical layout and resources, policies, and neonatal staff's attitude).

\section{REFERENCES}

1. Yaffe S. Foreword. Neonatal intensive care: a history of excellence. A symposium commemorating child health day. NIH Publication No 92-2786. 
www.neonatology.org/classics/nic.nih1985.pdf\#page4. Published October 1992. Accessed April 16, 2016.

2. Gooding JS, Cooper LG, Blaine BA, Franck LS, Howse JL, Berns SD. Family support and family centered care in the neonatal intensive care unit: origins, advances, impact. Semin Perinatol. 2011;35:20-28.

3. Sheeran N, Jones L, Rowe J. The relationship between maternal age, communication and supportive relationships in the neonatal nursery for mothers of preterm infants. J Neonatal Nurs. 2013;19:327-336.

4. McGrath JM. Building relationships with families in the NICU: exploring the guarded alliance. J Perinat Neonatal Nurs. 2001;15(3):74-83.

5. McGrath JM, Samra HA, Kenner C. Family centered developmental care practices and research: what will the next century bring? J Perinat Neonatal Nurs. 2011;25(2):165-170.

6. Johnson B, Jeppson E, Redburn L. Caring for the Children and Families: Guidelines for Hospitals. Bethesda, MD: Association for the Care of Children's Health; 1992.

7. Purdy IB, Craig JW, Zeanah P. NICU discharge planning and beyond: recommendations for parent psychosocial support. J Perinatology. 2015;35(suppl 1):S24-S28. www.ncbi.nlm.nih.gov/pmc/articles/PMC4660049. Accessed April 16, 2016.

8. Reynolds LC, Duncan MM, Pineda RG. Parental presence and holding in the neonatal intensive care unit and associations with early neurobehavior. J Perinatol. 2013;33(8):636641. www.ncbi.nlm.nig.gov/pmc/articles/PMC3700586. Accessed April 16, 2016.

9. Parker L. Mothers' experience of receiving counselling/psychotherapy on a neonatal intensive care unit (NICU). J Neonatal Nurs. 2011;17:182-189.

10. Rode H. The rise and fall of children's hospitals in South Africa. S Afr Med J. 2006;96(9):849-853.

11. Silverman WA. Incubator-Baby Side Shows. Pediatrics. 1979;64(2):127-141. www.neonatology.org/classics/silverman/silverman1.html\#12. Accessed April 16, 2016.

12. Gluck L. Conceptualization and initiation of a neonatal intensive care nursery in 1960. Neonatal intensive care: a history of excellence-a symposium commemorating child health day. NIH Publication No 92-2786. www.neonatology.org/classics/nic.nih1985.pdf\#page4. Published October 1992. Accessed April 16, 2016.

13. Gartner LM, Gartner CN. The care of premature infants: historical perspective. Neonatal intensive care: a history of excellence - a symposium commemorating child health day. NIH Publication No 92-2786. www.neonatology.org/classics/nic.nih1985.pdf\#page4. Published October 1992. Accessed April 16, 2016.

14. Duxbury M, Adams LR. Nursing research contributions to improve NICU care. Neonatal intensive care: a history of excellence - a symposium commemorating child health day. NIH Publication No 92-2786. www.neonatology.org/classics/nic.nih1985.pdf\#page4 Published October 1992. Accessed April 16, 2016.

15. Davis L, Mohay H, Edwards H. Mothers' involvement in caring for their premature infants: an historical review. J Adv Nurs. 2003;42(6):578-586.

16. Auerbach KG. All nurses in ante and postnatal wards can be involved in forming and supporting breastfeeding. J Adv Nurs. 1979;4:263-285.

17. Dunn DM, White DG. Interactions of mothers with their newborns in the first half-hour of life. J Adv Nurs. 1981;6(4):271-275. 
18. Bialoskurski MM, Cox CL, Wiggens RD. The relationship between maternal needs and priorities in a neonatal intensive care environment. J Adv Nurs. 2002;37(1):62-69.

19. Cuttini M, Rebagliato $M$, Bortoli $P$, et al. Parental visiting, communication and participation in ethical decisions: a comparison of neonatal unit policies in Europe. Arch Dis Child Fetal Neonatal Ed. 1999;81:F84-F91.

20. Hunt $F$. The importance of kangaroo care on infant oxygen saturation levels and bonding. J Neonatal Nurs. 2008;14(2):47-51.

21. Flynn A, Leahy-Warren P. Neonatal nurses' knowledge and beliefs regarding kangaroo care with preterm infants in an Irish neonatal unit. J Neonatal Nurs. 2010;16(5):221-228.

22. Cruse P, Yudkin P, Baum JD. Establishing demand feeding in hospital. Arch Dis Child. 1978;53(1):76-78.

23. Broadfoot M, Britten J, Tappin D, MacKenzie J. The baby friendly hospital initiative and breastfeeding rates in Scotland. Arch Dis Child Fetal Neonatal Ed. 2005;90:F114-F116.

24. Strong G. Barriers to breast-feeding during the neonatal period. J Neonatal Nurs. 2013;19(4):134-138.

25. Johnson K. Maternal-infant bonding: a review of literature. Int J Childbirth Ed. 2013;28(3):17-22.

26. Ramezani T, Shirazi ZH, Sarvestani RS, Moattari M. Family-centered care in neonatal intensive care unit: a concept analysis. Int J Community Based Nurs Midwifery.

2014;2(4):268-278. www.ncbi.nlm.nih.gov/pmc/articles/PMC4201206. Accessed June 6, 2015.

27. Sizun J, Westrup B, The ESF Network Coordination Committee. Early developmental care for preterm neonates: a call for more research. Arch Dis Child Fetal Neonatal Ed. 2004;89:F384-F389.

28. Zhou H, Shields L, Watts R, Taylor M, Munns A, Ngune I. Family-centred care for hospitalized children aged 0-12 years: a systematic review of qualitative studies. JBI Database Syst Rev Implement Rep. 2012;10(57):3917-3935.

www.joannabriggslibrary.org/index.php/jbisrir/article/view/78/92. Accessed April 16, 2016.

29. O'Brien K, Bracht M, Macdonell K, et al. A pilot cohort analytic study of family integrated care in a neonatal intensive care unit. BMC Preg Childbirth. 2013;13(suppl 1):S12.

30. Avon Premature Infant Project. Randomised trial of parental support for families with very preterm children. Arch Dis Child Fetal Neonatal Ed. 1998;79:F4-F11.

31. Redshaw M. Infants in neonatal intensive care unit: parental response. Arch Dis Child Fetal Neonatal Ed. 2005;90(2):F96

32. Lindberg B, Axelsson K, Ohrling K. The birth of premature infants: experiences from the fathers' perspective. J Neonatal Nurs. 2007;13(4):142-149.

33. Fenwick J, Barclay L, Schmied V. Struggling to mother: a consequence of inhibitive nursing interactions in the neonatal nursery. J Perinat Neonatal Nurs. 2001;15(2):49-64.

34. McHaffie HE. Social support in the neonatal intensive care unit. J Adv Nurs. 1992;17:279-287.

35. Levick J, Quinn M, Holder A, Nyberg A, Beaumont E, Munch S. Support for siblings of NICU patients: an interdisciplinary approach. Soc Work Health Care. 2010;49(10):919-933. .

36. Nichols A. Sustainable family centered care in the neonatal unit. J Neonatal Nurs. 2013;19:266-270. . 
37. Hall EOC, Brinchmann BS. Mothers of preterm infants: experiences of space, tone and transfer in the neonatal care unit. J Neonatal Nurs. 2009;15(4):129-136. .

38. Ballweg DD. Implementing developmentally supportive family centered care in the newborn intensive care unit as a quality improvement initiative. J Perinat Neonatal Nurs. 2001;15(3):58-73. Ovid HTML Full Text Internet Resources Bibliographic Links .

39. Griffin T. Family centered care in the NICU. J Perinat Neonatal Nurs. 2006;20(1):98102. Ovid HTML Full Text Internet Resources Bibliographic Links .

40. Registered Nurses' Association of Ontario. Best practice guidelines: person- and familycentred care. Toronto, ON, Canada: Registered Nurses' Association of Ontario; 2015. www.rnao.ca/bpg/guidelines/person-and-family-centred-care. Accessed April 16, 2016. .

41. Griffin T, Celenza J. Family-Centered Care for the Newborn. New York, NY: Springer, 2014.

42. Institute for Patient- and Family-Centered Care (IPFCC). The IPFCC Web site. www.ipfcc.org. Accessed May 20, 2016. 